\title{
Recommendations of the Brazilian Society of Rheumatology for the use of JAK inhibitors in the management of rheumatoid arthritis
}

\author{
Karina Rossi Bonfiglioli ${ }^{*}$ (D, Licia Maria Henrique da Mota ${ }^{2}$, Ana Cristina de Medeiros Ribeiro', \\ Adriana Maria Kakehasi ${ }^{3}$, leda Maria Magalhães Laurindo ${ }^{4}$, Rina Dalva Neubarth Giorgi ${ }^{5}$, \\ Angela Luzia Branco Pinto Duarte ${ }^{6}$, Ana Paula Monteiro Gomides Reis², \\ Mariana Peixoto Guimarães Ubirajara e Silva de Souza ${ }^{7}$, Claiton Viegas Brenol ${ }^{8}$, \\ Geraldo da Rocha Castelar Pinheiro ${ }^{9}$, Cleandro Pires de Albuquerque ${ }^{2}$, Charlles Heldan de Moura Castro ${ }^{10}$, \\ Gustavo Luiz Behrens Pinto ${ }^{11}$, Jose Fernando Verztman ${ }^{12}$, Luciana Feitosa Muniz ${ }^{13}$, Manoel Barros Bertolo ${ }^{14}$, \\ Maria Raquel da Costa Pinto ${ }^{3}$, Paulo Louzada Júnior ${ }^{15}$, Vitor Alves Cruz ${ }^{16}$, Ivanio Alves Pereira ${ }^{17}$, \\ Max Vitor Carioca de Freitas ${ }^{18}$, Bóris Afonso $\mathrm{Cruz}^{19}$, Eduardo Paiva ${ }^{20}$, Odirlei Monticielo ${ }^{8}$, \\ José Roberto Provenza ${ }^{21}$ and Ricardo Machado Xavier ${ }^{8}$
}

\begin{abstract}
Rheumatoid arthritis (RA) is a chronic and autoimmune systemic inflammatory disease that can cause irreversible joint deformities, with increased morbidity and mortality and a significant impact on the quality of life of the affected individual. The main objective of RA treatment is to achieve sustained clinical remission or low disease activity. However, up to $40 \%$ of patients do not respond to available treatments, including bDMARDs. New therapeutic targets for RA are emerging, such as Janus kinases (JAKs). These are essential for intracellular signaling (via JAK-STAT) in response to many cytokines involved in RA immunopathogenesis. JAK inhibitors (JAKi) have established themselves as a highly effective treatment, gaining increasing space in the therapeutic arsenal for the treatment of RA. The current recommendations aim to present a review of the main aspects related to the efficacy and safety of JAKis in RA patients, and to update the recommendations and treatment algorithm proposed by the Brazilian Society of Rheumatology in 2017.
\end{abstract}

\section{Introduction}

Rheumatoid arthritis (RA) is a chronic and autoimmune systemic inflammatory disease characterized by involvement of the synovial membrane of peripheral joints. If not treated early and adequately, the disease can cause bone erosion and irreversible joint deformities, with

\footnotetext{
*Correspondence: karina.bonfiglioli@hc.fm.usp.br

1 Disciplina Reumatologia do Hospital das Clínicas, Faculdade de

Medicina, Universidade de São Paulo (HC-FMUSP), Av. Dr. Arnaldo, 455 - $3^{\circ}$ andar - Reumatologia, São Paulo, SP, CEP 01246-903, Brasil

Full list of author information is available at the end of the article
}

increased morbidity and mortality and a significant impact on the quality of life of the affected individual [1]. RA affects up to $1 \%$ of the general population and is more common in women aged 40 to 60 years [2].

In the last 3 decades, there has been significant evolution in the management of patients with RA, with emphases on early diagnosis, rigorous monitoring of disease activity and goal-oriented treatment strategies. A better understanding of its pathophysiology has led to the development of new disease-modifying antirheumatic drugs (DMARDs), primarily biological DMARDs original author(s) and the source, provide a link to the Creative Commons licence, and indicate if changes were made. The images or other third party material in this article are included in the article's Creative Commons licence, unless indicated otherwise in a credit line to the material. If material is not included in the article's Creative Commons licence and your intended use is not permitted by statutory regulation or exceeds the permitted use, you will need to obtain permission directly from the copyright holder. To view a copy of this licence, visit http://creativecommons.org/licenses/by/4.0/. 
(bDMARDs) and, more recently, targeted synthetic DMARDs (tsDMARDs). The treatment objectives remain reducing joint and systemic inflammation with the aims of inhibiting disease progression, preventing loss of functionality and preserving patient quality of life [3-5].

Despite the various therapeutic options available, there are patients who do not achieve the desired response (remission or low disease activity) due to an inadequate clinical response (primary failure) or loss of response (secondary failure) or drug toxicity [6].

According to the most recent recommendations of the Brazilian Society of Rheumatology (SBR, for its initials in Portuguese) [1] and the European Alliance of Associations for Rheumatology (EULAR) [7], the main objective of RA treatment is to achieve sustained clinical remission or, in cases where this is not possible, low disease activity. However, up to $40 \%$ of patients do not respond to available treatments, including bDMARDs $[1,7]$.

New RA therapeutic targets are emerging. Janus kinases (JAKs), enzimes involved in intracellular signaling (JAK-STAT pathway), are essential to the control of response of many cytokines involved in the immunopathogenesis of RA. Therefore, JAK inhibitors (JAKis) have shown efficacy in the treatment of RA [8]. JAKis currently approved for commercialization in Brazil include tofacitinib [9] (JAK1 and JAK3 inhibitor), baricitinib [10] (JAK1 and JAK2 inhibitor) and upadacitinib [11] (selective JAK1 inhibitor).

\section{Objective}

The objective of these recommendations is to present a review, directed to rheumatologists, of the main aspects related to the efficacy and safety of JAKis in RA patients and to update the recommendations and treatment algorithm proposed by the SBR in 2017 [1].

\section{Method}

This review followed a protocol developed by the members of the SBR Rheumatoid Arthritis Committee, who established questions based on real-life scenarios, that can be accessed in Additional files.

For the purposes of these recommendations, the following acronym and nomenclature system was adopted:

DMARDs

csDMARDs
tsDMARDs

bDMARDs

JAKi

mTSS

HAQ-DI

NSAIDs

DAS28-CRP

DAS28-ESR

CDAI

SDAI

Remission

Low disease activity

RCT
Targeted synthetic diseasemodifying antirheumatic drugs (JAK inhibitors)-baricitinib (BARI), tofacitinib (TOFA), upadacitinib (UPA), filgotinib (FILGO) and peficitinib (PEFI); Biological disease-modifying antirheumatic drugs-tumor necrosis factor (TNF $\alpha-i)$ inhibitors adalimumab (ADA), certolizumab (CTZ), etanercept (ETA), golimumab (GOLI) and infliximab (IFX) and drugs with other mechanisms of non$\mathrm{TNF} \alpha-\mathrm{i}$ action, i.e., abatacept (ABA), rituximab (RTX) and tocilizumab (TCZ);

Janus Kinase inhibitor

Modified total Sharp score;

Health Assessment Questionnaire Disability Index;

Nonsteroidal antiinflammatory drugs;

Disease activity score 28/C-reactive protein.

Disease activity score 28/erythrocyte sedimentation rate.

Clinical Disease Activity Index.

Simplified Disease Activity Index.

DAS28-CRP and/or DAS28ESR $<2.6$; and.

DAS28-CRP and/or

DAS28-ESR $\geq 2.6<3.2$.

Randomized controlled trial.

To answer the selected questions, systematic literature reviews (SLRs) were performed for each specific scenario.

\section{Elements of study eligibility}

The search for evidence was performed in virtual scientific information databases using search strategies specific to each question.

The searches in these databases were performed until the month corresponding to the completion and submission of these guidelines for publication, and a systematic review was performed in accordance with the Preferred Reporting Items for Systematic reviews and Meta-Analyses (PRISMA) guidelines [12].

The following data were extracted from the studies: name of the author and year of publication, population 
studied, methods of intervention and comparison, absolute number of events, and follow-up time.

The risk of bias in randomized clinical trials was analyzed based on the following criteria: randomization, blinded allocation, double blinding, losses, prognostic characteristics, presence of expected outcome, time to outcome, outcome measurement method, sample calculation, early interruption, and presence of other biases.

The measures used to express benefits and harms varied based on the outcomes and were expressed as continuous variables (mean and standard deviation) or categorical variables (absolute number of events). For continuous measures, the results reflect differences in means and standard deviation, and for categorical measures, the results reflect differences in risks and number needed to treat or produce harm, considering the number of patients. The confidence level was set at $95 \%$. The results underwent meta-analysis when common outcomes among studies were observed.

The results of the included studies were aggregated and meta-analyzed using RevMan 5.4 software [13].

In addition, the quality of the evidence was scored as high, moderate, low or very low using the Grades of Recommendation, Assessment, Development, and Evaluation (GRADE) instrument [14], taking into account the risk of bias, the presence of inconsistencies, imprecise or indirect evidence in the meta-analysis of outcomes and the presence of publication bias.

The search strategies, selection process, characteristics and evaluation of the methodological quality of the included studies, as well as the synthesis of the results and quality of the evidence (based on GRADE), are available online as appendices.

\section{Elaboration of recommendations}

The process of drafting the recommendations relied on the participation of the SBR Rheumatoid Arthritis Committee, that included 27 rheumatologists from a panel of experts. Based on the SLR results for each clinical question as well as on the clinical experience of the experts, recommendations were elaborated and subjected to online voting.

The first step involved agreeing about the structure and content of each of the propositions, requiring $70 \%$ agreement for inclusion of the proposition. When this value was not attained, the propositions were reformulated and submitted to a new voting stage until $70 \%$ agreement was met. Subsequently, the level of agreement was established based on the content in the propositions: the panel of experts assigned a degree of agreement using a numerical scale from 0 ("strongly disagree") to 10 ("strongly agree") for each recommendation.

\section{Results}

A summary of the search and synthesis of the evidence for each SLR performed is presented below, based on the proposed clinical questions. In all scenarios, adult patients ( $>18$ years old) who met the RA classification criteria of the American College of Rheumatology (ACR) of 1987 [15] or the 2010 ACR/EULAR criteria [16] were evaluated. All the details on the selection of studies, reasons for exclusion, list of excluded studies, and analysis of the quality of the evidence for the outcomes are available in the corresponding appendices of this publication.

\section{Efficacy and safety of tsDMARDs (JAKis) under different scenarios}

\section{Are tsDMARDs (JAKis) safe and effective as a first- line treatment for RA patients? (ps.: treatment-naïve patients)}

A total of 403 studies were retrieved, individually accessed by title and/or abstract but only 3 were selected to support this evaluation. The reasons for exclusion and the list of excluded studies are available in the Additional file 1: Appendix 1 of this publication [17-19].

\section{Evidence summary}

The following evidence pertains to adult patients with recent onset RA (symptoms $<6$ months) or established RA (symptoms $\geq 6$ months), regardless of disease activity, who received a nontherapeutic dose or no csDMARDs/ bDMARDs.

\section{Results within 6 months}

- TOFA (5 mg 12/12 h), BARI (4 mg/day) and UPA (15 or $30 \mathrm{mg} /$ day), all in monotherapy, compared to MTX, led to a higher proportion of patients who achieved ACR (20\%-50\%-70\%) and DAS28-ESR (remission and low activity) responses. There was also more significant improvement in functional capacity (measured by the HAQ-DI) in patients who received TOFA, BARI and UPA monotherapy. The quality of the evidence supporting these results is high.

- BARI (4 mg/day) monotherapy compared to BARI+MTX did not show superiority in any response criterion.

\section{Results within 13 months}

- BARI (4 mg/day) compared to MTX, both monotherapies, led to a higher proportion of patients who achieved an ACR response (20\%-50\%-70\%) but not DAS28-ESR (remission or low activity). There was also more significant improvement in functional 
capacity, as measured by HAQ-DI. The quality of the evidence supporting this result is high.

- BARI (4 mg/day) monotherapy compared to BARI + MTX combined therapy showed no superiority in any response criterion.

- BARI (4 mg/day)+MTX combined therapy compared to MTX monotherapy led to a higher proportion of patients who achieved DAS28-ESR (remission and low activity). The quality of the evidence supporting this result is high.

\section{Safety}

- TOFA (5 mg 12/12 h) monotherapy and BARI (4 mg/ day) monotherapy or in combination with MTX demonstrated acceptable safety compared to MTX monotherapy in the initial treatment of patients with active RA, based on assessments of severe adverse events (SAEs). The quality of the evidence supporting this result is high.

- MTX and UPA (15 mg/day) showed similar occurrences of SAEs. However, UPA at a dose of $30 \mathrm{mg} /$ day had a higher risk of SAEs. The quality of the evidence supporting this result is moderate.

\section{Are tsDMARDs (JAKis) safe and effective for the treat- ment of RA patients after CsDMARD failure?}

The search for evidence resulted in a total of 1658 articles. After reading the titles and abstracts, 1581 studies were excluded. The full texts of 77 studies were accessed, of which 19 [20-38] were selected to support this evaluation. (Additional file 2: Appendix 2).

\section{Evidence summary}

The following evidence pertains to patients with moderate or high RA activity after DMARD failure, followed by treatment with a JAKi.

In monotherapy or in combination with MTX/other csDMARDs, or,

Compared with placebo in combination with MTX/ other csDMARDs.

- TOFA (5 mg 12/12 h or $10 \mathrm{mg}$ 12/12 h), alone or combined with MTX, improves ACR response outcomes (20\%-50\%-70\%) and DAS28-ESR (remission and low activity). There was also improvement in functional capacity (measured by the HAQ-DI). The quality of evidence supporting this result is high.

- BARI (2 mg/day and $4 \mathrm{mg} /$ day) monotherapy or combined with MTX led to a higher proportion of patients who achieved an ACR response (20\%-50\%$70 \%)$ and low disease activity and remission, as determined by DAS28-CRP and DAS28-ESR, in addition to significant improvement in functional capacity (as measured by the HAQ-DI). The quality of the evidence supporting this result is high/moderate.

- UPA (15 mg/day) monotherapy or combined with MTX led to a higher proportion of patients who achieved an ACR response (20-50-70) and low disease activity and remission, as determined by DAS28-CRP and DAS28-ESR. The quality of the evidence supporting this result is high/moderate.

- FILGO (100 mg/day and $200 \mathrm{mg} /$ day) monotherapy led to a higher proportion of patients who achieved ACR 50, ACR 70, and low disease activity, as determined by DAS28-CRP and DAS28-ESR, with moderate quality of evidence. However, the quality of evidence for improvements in ACR 20 and the HAQDI score are moderate and low, respectively. PEFI (100 mg/day and $150 \mathrm{mg} /$ day) as a monotherapy or combined with MTX led to a higher proportion of patients who achieved an ACR response (20-5070), remission, as determined by DAS28-CRP and DAS28-ESR, and low disease activity, as determined by DAS28-CRP. The quality of the evidence supporting this result is low/very low.

\section{Safety}

All JAKis, alone or in combination with MTX, showed acceptable safety compared to placebo for patients with moderate or high RA after failure of regimens with different csDMARDs, as determined by analyzing SAEs. The quality of evidence for this outcome ranged from moderate to very low. To better understand/define the safety of JAKis, more phase 4 studies are needed.

\section{Are tsDMARDs (JAKis) safe and effective for the treat- ment of RA patients after bDMARD failure?}

In the search for evidence, 58 studies were retrieved and individually assessed by title and/or abstract; 4 [3942] references were selected for evaluation of their full texts. (Additional file 3: Appendix 3).

\section{Evidence summary}

The following evidence pertains to patients with a diagnosis of established RA who had an inadequate response to treatment with bDMARDs, followed by treatment with tsDMARDs (JAKis), either as a monotherapy or in combination with methotrexate or other csDMARDs, in comparison with placebo.

\section{Results within 3 months}


- TOFA, BARI, and FILGO led to a higher proportion of patients who achieved an ACR response $(20 \%-$ $50 \%-70 \%$ ) in 3 months.

- UPA led to a higher proportion of patients who achieved ACR 20 and 50 responses in 3 months.

- TOFA led to a higher proportion of patients who reached low activity (DAS28-ESR) in 3 months.

- BARI led to a higher proportion of patients who achieved low activity and remission (DAS28-ESR) in 3 months.

- FILGO and UPA led to a higher proportion of patients who reached low activity (DAS28-CRP) in 3 months.

- There was improvement in functional capacity (measured by HAQ-DI) for all JAKis, in 3 months.

- The quality of the evidence supporting these results is high.

\section{Safety}

All JAKis, alone or in combination with MTX, after failure of bDMARDs, showed acceptable safety compared to placebo, as determined by analyzing SAEs. The quality of evidence supporting these results is high.

\section{Effectiveness, safety and cost of tsDMARDs (JAKis) in relation to csDMARDs and bDMARDs}

\section{Are tsDMARDs (JAKis) more effective than csD- $M A R D$ s in the treatment of RA?}

In the search for evidence, 1325 studies were retrieved and individually assessed by title and/or abstract, from which 42 references were selected for evaluation of their full texts. Of the 42 studies, $4[17,19,43,44]$ randomized clinical trials were selected to support this evaluation, i.e., JAKis (TOFA, BARI and UPA) compared with MTX. A flow diagram is provided in the online supplementary Additional file 4: Appendix 4.

\section{Evidence summary}

The following evidence pertains to adult patients who met the RA classification criteria of the ACR or ACR/ EULAR 2010 and in whom the the use of JAKis (TOFA, BARI and UPA) and csDMARDs (MTX) was compared.

\section{Results within 3-6 months}

- UPA (15 mg/day and $30 \mathrm{mg} /$ day) monotherapy, compared to MTX, led to a higher proportion of patients who achieved ACR 20\% and 50\% responses in 3 months. A higher proportion of patients also achieved clinical remission (DAS28-PCR) in 6 months. The quality of the evidence supporting this result is high.
- Compared with MTX, UPA (15 mg/day and $30 \mathrm{mg} /$ day) after 6 months resulted in lower radiographic progression (Van der Heijde score) of RA. The quality of the evidence supporting this result is high.

\section{Results within 6-12 months}

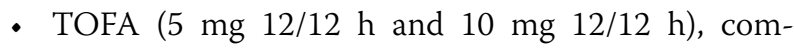
pared to MTX, both monotherapies, led to a higher proportion of patients who achieved an ACR (20$50 \%)$ response and low activity (DAS28-ESR). In 12 months, an ACR 70\% response rate and remission, as determined by DAS28-ESR, were more frequent in patients who received TOFA. The quality of the evidence supporting this result is high.

- Compared with MTX, TOFA (5 mg 12/12 h and

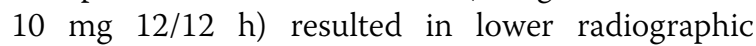
progression (modified Van der Heijde score) at 6 months. The quality of the evidence supporting this result is high.

- Compared to MTX, BARI (4 mg/day) monotherapy (or combined with MTX) led to a higher proportion of patients who achieved an ACR response (20\%$50 \%-70 \%)$ and clinical remission (DAS28-ESR) at 6 and 12 months. The quality of the evidence supporting this result is high.

- Compared with MTX, BARI (4 mg/day) did not alter the risk of radiographic progression (Van der Heijde score). The quality of the evidence supporting this result is high.

\section{Safety}

- Compared with MTX monotherapy, TOFA (5 mg) monotherapy and BARI $(4 \mathrm{mg})$ monotherapy or in combination with MTX demonstrated acceptable safety in the initial treatment of patients with active RA, as determined by analyzing SAEs. The quality of the evidence supporting this result is high.

- The adverse events resulting from treatment with MTX and UPA (15 mg/day) were similar, but there was a higher incidence of adverse events with $30 \mathrm{mg} /$ day UPA. The quality of the evidence supporting this result is moderate.

\section{Compared with bDMARDs, do tsDMARDs (JAKis) show evidence of greater efficacy for the treatment of $R A$ ?}

In the search for evidence, 1442 studies were retrieved and individually assessed by title and/or abstract, from which 33 references were selected for evaluation of their 
full texts. Of the 33 studies selected to support this evaluation, there were only 4 [45-48] randomized clinical trials that compared TOFA, BARI or UPA with ADA in combination with MTX. A flow diagram is provided in the Additional file 5: Appendix 5.

\section{Evidence summary}

The following evidence pertains to adult patients (>16 years) with recent onset RA (symptoms $<6$ months) and established RA (symptoms $\geq 6$ months), regardless of disease activity, in whom the use of JAKis as a monotherapy or in combination with MTX was compared with the use of bDMARDs alone or combined with MTX.

\section{Results within 6 months}

- Compared to ADA + MTX, TOFA (5 mg 12/12 h) as a monotherapy did not led to different ACR 20\%, ACR $50 \%$, and ACR 70\% outcomes and was inferior to ADA + MTX regarding low activity outcomes (DAS28-ESR).

- TOFA (10 mg 12/12 h) was superior to ADA+MTX combined therapy with respect to ACR $70 \%$ outcomes; there was no difference between the treatments for the other outcomes. The quality of the evidence supporting this result is moderate.

- UPA (15 mg/day) combined with MTX, compared to ADA + MTX, led to a higher proportion of patients who achieved ACR 20\% and 50\% responses. The quality of the evidence supporting this result is moderate.

- Compared with ADA+MTX, UPA (15 mg/day) combined with MTX did not reduce the risk of radiographic progression (mTSS). The quality of the evidence supporting this result is moderate.

\section{Results within 12 months}

- Compared with ADA + MTX, TOFA (5 mg 12/12 h) as a monotherapy did not alter ACR $20 \%, 50 \%$, and $70 \%$ outcomes and resulted in lower low activity and remission outcomes (DAS28-VHS) at 12 months.

- BARI (4 mg/day) combined with MTX, compared to ADA + MTX, led to a higher proportion of patients who achieved ACR 20\% and 50\% responses, with no difference for ACR 70\% outcomes, remission and low activity (DAS28-PCR). The quality of the evidence supporting this result is moderate.

- Compared with ADA + MTX, BARI (4 mg/day) combined with MTX reduced the risk of radiographic progression (mTSS) at 6 and 12 months. The quality of the evidence supporting this result is moderate.

\section{Safety}

- The rate of SAEs at 6 and 12 months was higher in patients who used BARI than in those who used ADA. There was no difference in SAEs when comparing those for TOFA or UPA with ADA at the 6-month follow-up. The quality of the evidence supporting this result is moderate.

\section{Is there evidence of better cost-effectiveness for DMARDs (JAKis) compared with csDMARDs?}

In the search for evidence, 203 studies were retrieved and individually assessed by title and/or abstract, from which 16 references were selected for full text evaluation. Of the 16 studies, only 2 were selected to support this evaluation $[49,50]$. A flow diagram is provided in the online supplementary Additional file 6: Appendix 6 .

\section{Evidence summary}

In patients with moderate to severe active RA, tsDMARDs (JAKis), compared with csDMARDs, were cost-effective in patients with inadequate responses to biological therapy.

The literature, however, lacks studies that evaluate whether tsDMARDs are cost-effective when compared with csDMARDs after failure with another csDMARD. Future studies are needed to evaluate this scenario.

\section{Is there evidence of better cost-effectiveness for tsD- MARDs (JAKis) compared with bDMARDs?}

Studies were evaluated for risk of bias using the Critical Appraisal Skills Program-CASP (economic) evaluation checklist [1]. In the search for evidence, 203 studies were retrieved and individually assessed by title and/or abstract, of which 16 references were selected for full text evaluation. Of the 16 studies, only 6 were selected to support this evaluation [51-57]. Supporting material is available online in the supplementary Additional file 7: Appendix 7.

\section{Evidence summary}

- Compared with the use of biological therapies (ADA, ETA, CERTOLI, RITUXI, ABATA and TOCILI), the use of JAKis (BARI and TOFA combined or not with MTX) is cost-effective in patients with active, moderate to severe RA, with inadequate response to csDMARDs or anti-TNF bDMARDs. 
- Future studies are needed to evaluate the cost-effectiveness of JAKis compared to that of DMARDs in the Brazilian scenario, as well as the cost-effectiveness of other JAKis.

\section{Is there evidence for vaccination effectiveness against herpes zoster $(\mathrm{HZ})$ before starting treatment with JAKis?}

Evidence indicates that the use of JAKis is accompanied by a higher risk of infection by $\mathrm{HZ}[58,59]$.

In the search for evidence, 1909 studies were retrieved and individually assessed by title and/or abstract, from which 19 references were selected for full text evaluation. Finally, in regard to the eligibility criteria, 4 studies were included [60-63]; the reasons for exclusion are found in the online supplementary Additional file 8: Appendix 8.

\section{Evidence summary}

- The efficacy of the live attenuated HZ vaccine (LZV) is questionable in patients using JAKis, especially in combination with MTX. The quality of the evidence supporting this result is moderate.

- Therapy with TOFA has no negative impact on the established immune response after vaccination with LZV. The quality of the evidence supporting this result is moderate.

- Therapy with TOFA has no impact on the incidence of HZ during patient follow-up after LZV vaccination. The quality of the evidence supporting this result is moderate

\section{Is there evidence of a higher risk of venous thrombo- embolic events (VTEs) related to JAKi treatment?}

In the search for evidence, 1541 studies (RCT) were retrieved and individually assessed by title and/or abstract, from which 30 references were selected for full text evaluation. Of the 30 studies, 10 were selected to support this evaluation [64-73] (Fig. 1). The reasons for exclusion and the list of excluded studies, as well as the description of the included studies, are available in the Additional file 9: Appendix 9.

\section{Evidence summary}

The following evidence pertains to adult patients with RA who used tsDMARDs (JAKis) as a monotherapy or in combination with MTX or other csDMARDs.

- There was no significant increase in the risk of VTE.
- The use of low doses of JAKi seemed to offer a lower risk of VTE than high doses. The quality of the evidence supporting this result is high.

\section{Safety of JAKi in light of recent warnings}

Although the present SLR has not shown unexpected findings regarding safety within each of the questions that guided the search, the authors considered necessary to discuss some recent data not covered in the SLR search period.

On Oral Surveillance study [74], the prespecified noninferiority criteria for the co-primary endpoints of major adverse cardiovascular events (MACE) and malignancies (excluding non-melanoma skin cancer), were not met for the primary comparison of the combined tofacitinib doses (5 mg twice daily and $10 \mathrm{mg}$ twice daily) to TNF inhibitors (either etanercept $50 \mathrm{mg}$ once weekly or adalimumab 40 mg every other week).

However, despite this trial wrapping in July 2020,, its full results have been submitted but not yet published. Updates on this subject can be accessed at clinicaltrials. gov (https://clinicaltrials.gov/ct2/show/results/NCT02 092467).

In February 2021, a new "Food and Drug Administration" (FDA) warning regarding tofacitinib was issued [75]. FDA warned providers of an increased cardiovascular and cancer risk among older patients ( $>50$ years), compared with TNF-inhibitors. These warning has been based on interim and preliminary results from the ORAL Surveillance study [74].

In September 2021, FDA updated this previous warning, concluding that there is an increased risk of serious heart-related events such as heart attack or stroke, cancer, blood clots and death related with Tofacitinib. Based on that conclusion, required "Boxed warning" addings and revisions for all JAKi, including these findings and limiting all approved uses to certain patients who have not responded or cannot tolerate one or more TNF blockers [75].

European Medicines Agency (EMA) has also recommended an update to the product information for tofacitinib, and uttered a reminding to healthcare professionals to carefully evaluate a patient's individual benefit-risk profile when deciding to prescribe or continue the treatment [76].

Considering clinical aspects of the patients included in the post-marketing trial, who presented not only advanced age, but also other risk factors for unfavorable outcomes, we suggest taking into account the risk-benefit ratio when considering prescription of JAKi. For 


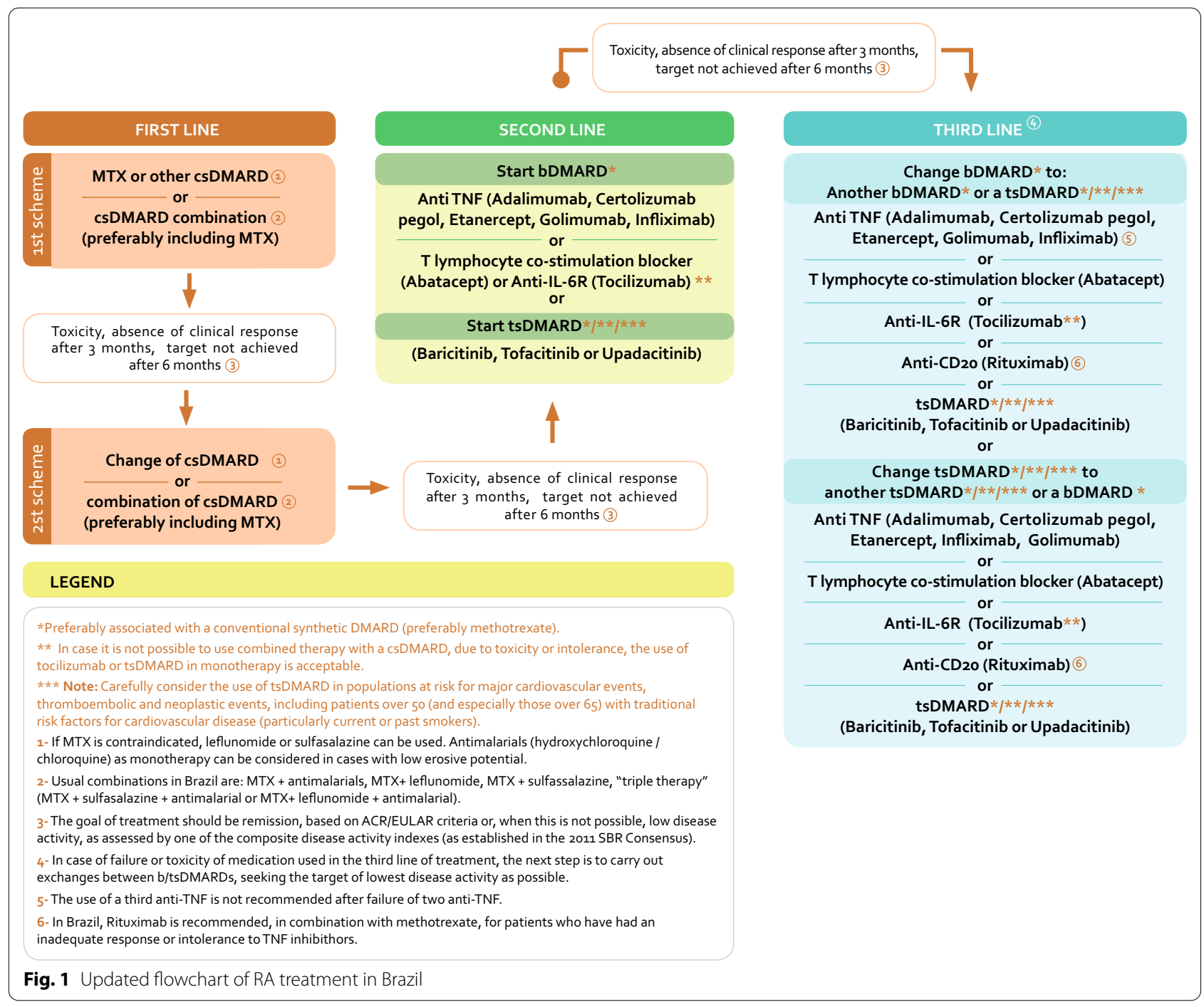

patients already receiving JAKi, strict surveillance of those who meet the high-risk profile is recommended.

Also taking into account the recent data, the SBR RA committee decided to re-vote recommendations 5 and 9 (see Table 1), and a warning note was included for JAKi prescription, as it follows:

Recommendation 5: After failure of 2 csDMARD regimens, a bDMARD or a tsDMARD can be used, preferably combined with a csDMARD. Note: Carefully consider the use of tsDMARD in populations at risk for major cardiovascular events, thromboembolic and neoplastic events, including patients over 50 (and especially those over 65) with traditional risk factors for disease cardiovascular (particularly current or past smokers).

Recommendation 9: In case of failure of a bDMARD as initial treatment, a second bDMARD or a tsDMARD can be used. Note: Carefully consider the use of tsDMARD in risk groups for major cardiovascular events, thromboembolic and neoplastic events, including patients over 50 (and especially those over 65 ) with traditional risk factors for cardiovascular disease (particularly current or past smokers).

\section{Update of general assumptions and recommendations of the SBR committee on rheumatoid arthritis}

Based on the data previously presented and the voting process described, the RA Commission updated the therapeutic recommendations for RA in relation to the previous document [1]. Table 1 summarizes the general assumptions and recommendations of the SBR Rheumatoid Arthritis Committee for pharmacological treatment of RA in Brazil. The ones included in the present recommendations $(5,8,9,10$ and 12) are highlighted in Table 1. 
Table 1 General assumptions and recommendations of the SBR for the drug treatment of RA in Brazil

\section{General assumptions}

1. The treatment of RA patients should preferably have a multidisciplinary approach, coordinated by a rheumatologist Degree of agreement: 9.9

2. Treatment of RA patients should include guidance on lifestyle, strict control of comorbidities and vaccination card updates Degree of agreement: 9.9

3. The treatment of RA patients should be based on decisions shared between patients and physicians, after clarification about their disease and available therapeutic options

Degree of agreement: 10

4. The goal of treatment is a persistent state of clinical remission or, when this is not possible, low disease activity Degree of agreement: 9.9

SBR recommendations for drug treatment of RA

Recommendation 1: First-line treatment should be performed with csDMARDs as soon as the diagnosis of RA is established Degree of agreement: 9.9

Recommendation 2: Methotrexate should be the first-choice csDMARD

Degree of agreement: 9.8

Recommendation 3: The combination of 2 or more csDMARDs, preferably including methotrexate, can be used as a first-line treatment Degree of agreement: 9.6

Recommendation 4: After failure of first-line methotrexate therapy, subsequent strategies include combination with another csDMARD, combination with 2 csDMARDs or exchanging MTX for another csDMARD as a monotherapy

Degree of agreement: 9.6

Recommendation 5: After failure of 2 csDMARD regimens, a bDMARD or a tsDMARD can be used, preferably combined with a csDMARD Note: Carefully consider the use of tsDMARD in populations at risk for major cardiovascular events, thromboembolic and neoplastic events, including patients over 50 (and especially those over 65) with traditional risk factors for cardiovascular disease (particularly current or past smokers).Degree of agreement: 8.6

Recommendation 6: The different bDMARDs combined with methotrexate have similar efficacy; therefore, the choice should take into account the particularities of each medication in terms of safety and cost

Degree of agreement: 9.6

Recommendation 7: The combination of b/tsDMARDs and methotrexate is preferred over the use of b/tsDMARDs as monotherapy. If monotherapy is necessary, consider preferentially the use of tocilizumab or tsDMARDs

Degree of agreement: 9.1

Recommendation 8: The different tsDMARDs have a similar efficacy profile; therefore, the choice should take into account the particularities of each medication in terms of safety and cost. Degree of agreement: 9.7

Recommendation 9: In case of failure of a bDMARD as initial treatment, a second bDMARD or a tsDMARD can be used

Note: Carefully consider the use of tsDMARD in populations at risk for major cardiovascular events, thromboembolic and neoplastic events, including patients over 50 (and especially those over 65) with traditional risk factors for cardiovascular disease (particularly current or past smokers).Degree of agreement: 9.0

Recommendation 10: In case of failure of a tsDMARD, another tsDMARD or a bDMARD may be used Degree of agreement: 9.4

Recommendation 11: Corticosteroids, preferably in low doses, for the shortest possible time, should be considered in periods of disease activity, after evaluating the relationship between risk and benefit

Degree of agreement: 9.7

Recommendation 12: The possibility of reduction, dose spacing or eventual discontinuation of bDMARDs or tsDMARDs can be considered in patients who are in persistent remission ( 6 to 12 months of remission), especially when the patient is using a tsDMARD

Degree of agreement: 9.2

Recommendations included in this update: $5,8,9,10$ and 12

$R A$ : rheumatoid arthritis; DMARDs: disease-modifying antirheumatic drugs; CSDMARDs: conventional synthetic disease-modifying antirheumatic drugs-methotrexate, leflunomide, sulfasalazine and hydroxychloroquine; tsDMARDs: targeted synthetic disease-modifying antirheumatic drugs-baricitinib, tofacitinib and upadacitinib; bDMARDs: biological disease-modifying antirheumatic drugs; bDMARDs: biological disease-modifying antirheumatic drugs that include: tumor necrosis factor inhibitor (TNFi), i.e., adalimumab, certolizumab, etanercept, golimumab and infliximab, and drugs with other non-TNFi mechanisms of action, i.e., abatacept, rituximab and tocilizumab; NSAIDs: nonsteroidal antiinflammatory drugs; Remission: remission according to ACR/EULAR criteria

\section{Flowchart for drug treatment of rheumatoid arthritis}

Figure 1 summarizes the updated flowchart for drug treatment of RA in Brazil proposed by the RA Commission of the SBR.

\section{Conclusions}

Important advances in the management of RA patients are leading a better patient prognosis. Rheumatologists, as specialist, are most familiar with the range of drugs available and their indications and adverse effects and are 
essential in the evaluation and treatment of patients diagnosed with RA.

The appropriate allocation of healthcare resources, especially in a country of continental dimensions and with a growing population, such as Brazil, conducts to access to drugs and appropriate technologies for the treatment of various conditions. These recommendations took into account, in addition to issues of safety, efficacy and cost, the experience of specialists in the management of RA, considering specific characteristics of Brazil, such as the availability of drugs and the socioeconomic level of the population.

Because the pace of knowledge acquisition in this field of science and the rise of new medications that are being analyzed for approval by Brazilian regulatory agencies, we recommend updating these guidelines every 2 years.

\section{Supplementary Information}

The online version contains supplementary material available at https://doi. org/10.1186/s42358-021-00228-x.

Additional file 1. PICO 1 - Are tsDMARD (JAK inhibitors) effective and safe for the treatment ofRA patients in 1st line of treatment? (NOTE: "naive" or treatment-naive patients).

Additional file 2. PICO 2 - Are tsDMARD (JAK inhibitors) effective and safe for the treatment ofRA patients after csdmard failure?

Additional file 3. PICO 3 - Are tsDMARD (JAK inhibitors) effective and safe for the treatment ofRA patients after bDMARD failure?

Additional file 4. PICO 4 - Are tsDMARD (JAK inhibitors) more effective for the treatment of patients with RA, compared to csDMARD?

Additional file 5. PICO 5 - Are tsDMARD (JAK inhibitors) more effective for the treatment ofpatients with RA compared to bDMARD?.

Additional file 6. PICO 6 - Is there any evidence of better cost-effectiveness of tsDMARD (JAKinhibitors) compared to csDMARD?.

Additional file 7. PICO 7 - Is there any evidence of better cost-effectiveness of tsDMARD (JAKinhibitors) compared to bDMARD?

Additional file 8. PICO 8 - Is there any evidence for herpes zoster vaccination eficcacybefore starting tsDMARD (JAK inhibitor) treatment?.

Additional file 9. PICO 9 - Is there evidence of an increased risk of thromboembolic events related to treatment withMMCDsae (JAK inhibitors)?.

\section{Acknowledgements}

The authors wish to acknowledge the researcher Wanderley Bernardo, who is responsible for the systematic review_-presented in detail in the supplementary material, funded by the Brazilian Society of Rheumatology.

\section{Authors' contributions}

All authors made substantial contributions to the acquisition of data, have been involved in drafting the manuscript or revising it critically for important intellectual content, gave final approval of the version to be published and have participated sufficiently in the work to take public responsibility for appropriate portions of the content; and agreed to be accountable for all aspects of the work in ensuring that questions related to the accuracy or integrity of any part of the work are appropriately investigated and resolved. All authors read and approved the final manuscript.
Funding

Brazilian Society of Rheumatology. The funding body had no role in the design of the study and collection, analysis, and interpretation of data and in writing the manuscript.

\section{Availability of data and materials}

All data generated or analyzed during this study are included in this published article, as "supplementary materials".

\section{Declarations}

Ethics approval and consent to participate

Not applicable.

\section{Consent for publication}

All authors have read and approved the final version of this manuscript.

\section{Competing interests}

Karina Rossi Bonfiglioli: Personal fees and/or non-financial support from Pfizer, Abbvie, Roche, Novartis, Boheringer-Ingelheim. Financial competing interest: none. Non-financial competing interest: none. Licia Maria Henrique da Mota: Has received personal or institutional support from Abbvie, Janssen, Pfizer and Roche; has delivered speeches at events related to this work and sponsored by Abbvie, Boheringer- Ingelheim, Janssen, Pfizer, Roche, Sandoz, Lilly and UCB. Financial competing interest: none. Non-financial competing interest: none. Ana Cristina de Medeiros Ribeiro: No conflicts declared. Adriana Maria Kakehasi: Research funds: CNPq, SBR, FAPEMIG Support for Scientific Events: Abbvie, BMS, Janssen Lecture Fees: UCB, Janssen, Pfizer, Roche, BMS Clinical research: Roche, Pfizer Advisory board: Janssen, Roche, BMS, Pfizer. Angela Luzia Branco Pinto Duarte: Lecture Fees: Janssen, BMS. Rina Dalva Neubarth Giorgi: Has received consulting fees,speaking fees and support for international congresses from: Roche,Pfizer,Bristol-Myers-Squibb, UCB Pharma, Eli-Lilly, AbbVie, Novartis, Amgen, Biogen and Janssen. leda Maria Magalhães Laurindo: Consultants for Abbvie,Amgen, Boehring-Ingelheim, Bristol, GSK, Janssen, Lilly, Pfizer and UCB; has received personal or institutional support from Abbvie, Bristol, Janssen, Lilly, Pfizer, UCB; has delivered speeches at events related to this work and sponsored by Abbvie, Bristol, Janssen, Lilly, Pfizer, Roche and UCB. Financial competing interest: none. Non-financial competing interest: none. Mariana Peixoto Guimarães Ubirajara e Silva de Souza: Suport for Research, Scientific Events, Lecture: UCB, Abbvie, BMS, Novartis, Pfizer, Amgen, Sandoz, Roche. Ana Paula Monteiro Gomides: Assistance for participation in events: Pfizer. Claiton Viegas Brenol: Has participated in clinical and/or experimental studies related to this work and sponsored by the PI (Abbvie, BMS, Janssen, Pfizer and Roche); has received personal or institutional support from the PI (Abbvie, BMS, Janssen, Pfizer and Roche); has delivered speeches at events related to this work and sponsored by the PI (Abbvie, Janssen, Pfizer and Roche). Financial competing interest: none. Non-financial competing interest: none. Geraldo da Rocha Castelar Pinheiro: No conflicts declared. Charlles Heldan de Moura Castro: No conflicts declared. Cleandro Pires de Albuquerque: Personal fees and/or non-financial support from Pfizer, Abbvie, AstraZeneca, Janssen, Bristol-Myers-Squibb, Roche, Novartis and UCB, outside the submitted article. Gustavo Luiz Behrens Pinto: Personal fees and/or non-financial support from Abbvie, Janssen, Roche and Novartis, outside the submitted article. Jose Fernando Verztman: personal fees and/or non-financial support from Pfizer, Abbvie, Roche, Novartis, Janssen, Lilly. Financial competing interest: none. Non-financial competing interest: none. Luciana Feitosa Muniz: No conflicts declared. Manoel Barros Bertolo: Has participated in clinical and/or experimental studies related to this work and sponsored by the PI (Roche); has delivered speeches at events related to this work and sponsored by the PI (Abbvie, Pfizer). Financial competing interest: none. Non-financial competing interest: none. Maria Raquel da Costa Pinto: Support in Congresses: UCB, Roche, Janssen, Bristol, Pfizer, Boheringer. Advisory Board: Janssen. Paulo Louzada Júnior: Sponsored by: Bristol-Myers Squibb, UCB, Pfizer Board Participation: Pfizer. Vitor Alves Cruz: Support in Congresses: UCB, Jansen, Abbvie and Pfizer. Ivanio Alves Pereira: Has received personal fee for lectures from Abbvie, Janssen, Pfizer and Roche; has delivered speeches at events related 
to this work and sponsored by Abbvie, Boheringer- Ingelheim, Janssen, Pfizer, Roche, Sandoz, Lilly and UCB. Financial competing interest: none. Non-financial competing interest: none. Max Vitor Carioca de Freitas: Speaker at events related to this work and sponsored by Abbvie, Novartis, Roche, Pfizer and UCB. Managing Partner of Integrare Therapeutics. Bóris Afonso Cruz: Support for Scientific Events and Lecture Fees: Abbvie, BMS, Janssen, Novartis, Pfizer, Roche. Eduardo Paiva: No conflicts declared. Odirlei Monticielo: Lectures and consultancies: Abbvie, APSEN, BMS, GSK, Janssen, Lilly, Novartis, Pfizer, Roche, UCB. José Roberto Provenza: No conflicts declared. Ricardo Machado Xavier: Lectures, consultancies: Abbvie, BMS, GSK, Janssen, Lilly, Novartis, Pfizer, Roche, UCB Clinical trials: Abbvie, UCB, Pfizer, GSK, Lilly.

\section{Author details}

'Disciplina Reumatologia do Hospital das Clínicas, Faculdade de Medicina, Universidade de São Paulo (HC-FMUSP), Av. Dr. Arnaldo, 455 - $3^{\circ}$ andar Reumatologia, São Paulo, SP, CEP 01246-903, Brasil. ${ }^{2}$ Serviço de Reumatologia do Hospital, Universitário de Brasília (HUB/UnB), Brasília, Brazil. ${ }^{3}$ Serviço de Reumatologia, Universidade Federal de Minas Gerais (UFMG), Belo Horizonte, Brazil. ${ }^{4}$ Disciplina de Reumatologia, Universidade Nove de Julho (UNINOVE), São Paulo, Brazil. ${ }^{5}$ Serviço de Reumatologia, Hospital do Servidor Público Estadual de São Paulo (HSPE-IAMSPE), São Paulo, Brazil. ${ }^{6}$ Universidade Federal de Pernambuco (UFPE), Recife, Brazil. ' Santa Casa de Belo Horizonte (MG), Belo Horizonte, Brazil. ${ }^{8}$ Hospital de Clínicas de Porto Alegre, Universidade Federal do Rio Grande do Sul (HCPA/UFRGS), Porto Alegre, Brazil. ${ }^{9}$ Universidade do Estado do Rio de Janeiro (UERJ), Rio de Janeiro, Brazil. ${ }^{10}$ Escola Paulista de Medicina, Universidade Federal de São Paulo, São Paulo, Brazil. ${ }^{11}$ Universidade Federal da Bahia (UFBA), Salvador, Brazil. ${ }^{12}$ Hospital Federal dos Servidores do Estado do RJ, Rio de Janeiro, Brazil. ${ }^{13}$ Hospital Regional de Sobradinho (DF), Brasília, Brazil. ${ }^{14}$ Disciplina de Reumatologia, Faculdade de Ciências Médicas, Universidade Estadual de Campinas, Campinas, Brazil. ${ }^{15}$ Disciplina de Reumatologia, Faculdade de Medicina de Ribeirão Preto, Universidade de São Paulo (USP-RP), Ribeirão Preto, Brazil. ${ }^{16}$ Disciplina de Reumatologia, Faculdade de Medicina, Universidade Federal de Goiás, Goiânia, Brazil. ${ }^{17}$ Serviço de Reumatologia do Hospital Universitário, Universidade Federal de Santa CatarinaUFSC, Florianópolis, Brazil. ${ }^{18}$ Universidade de Fortaleza - UNIFOR, Fortaleza, Brazil. ${ }^{19}$ Pulsus - Belo Horizonte (MG), Belo Horizonte, Brazil. ${ }^{20}$ Disciplina de Reumatologia, Universidade Federal do Paraná (UFPR), Curitiba, Brazil. ${ }^{21}$ Disciplina de Reumatologia da Pontificia, Universidade Católica de Campinas, PUC-Campinas, Campinas, Brazil.

\section{Received: 25 June 2021 Accepted: 5 November 2021}

Published online: 24 November 2021

\section{References}

1. Mota LMHD, Kakehasi AM, Gomides APM, et al. 2017 recommendations of the Brazilian Society of Rheumatology for the pharmacological treatment of rheumatoid arthritis. Adv Rheumatol. 2018;58(1):2. https://doi. org/10.1186/s42358-018-0005-0.

2. Alamanos Y, Voulgari PV, Drosos AA. Incidence and prevalence of rheumatoid arthritis, based on the 1987 American College of Rheumatologycriteria: a systematic review. Semin Arthritis Rheum. 2006;36:182-8.

3. Emery P, Salmon M. Early rheumatoid arthritis: time to aim for remission? Ann Rheum Dis. 1995;54:944-7.

4. Kavanaugh A. Economic consequences of established rheumatoid arthritis and its treatment. Best Pract Res Clin Rheumatol. 2007;21:929-42.

5. Klarenbeek NB, Allaart CF, Kerstens PJ, Huizinga TW, Dijkmans BA. The BeSt story: on strategy trials in rheumatoid arthritis. Curr Opin Rheumatol. 2009;21:291-8.

6. Ghabri S, Binard A, Pers YM, Maunoury F, Caro JJ. Economic evaluation of sequences of biological treatments for patients with moderate-tosevere rheumatoid arthritis and inadequate response or intolerance to methotrexate in France. Value Health. 2020;23(4):461-70. https://doi.org/ 10.1016/j.jval.2019.12.003.

7. Smolen JS, Landewé RBM, Bijlsma JWJ, et al. EULAR recommendations for the management of rheumatoid arthritis with synthetic and biological disease-modifying antirheumatic drugs: 2019 update. Ann Rheum Dis. 2020;79(6):685-99. https://doi.org/10.1136/annrheumdis-2019-216655.
8. Angelini J, Talotta R, Roncato R, et al. JAK-inhibitors for the treatment of rheumatoid arthritis: a focus on the present and an outlook on the future. Biomolecules. 2020;10(7):E1002. https://doi.org/10.3390/biom10071002.

9. Bula Tofacinib, Aug, 10, 2020.

10. Bula Bariticinite Aug, 10, 2020

11. Bula Upadacitinib.

12. Moher D, Shamseer L, Clarke M, Ghersi D, Liberati A, Petticrew M, Shekelle P, Stewart LA. Preferred Reporting Items for Systematic Review and Meta-Analysis Protocols (PRISMA-P) 2015 statement. Syst Rev. 2015;4(1):1. https://doi.org/10.1186/2046-4053-4-1.

13. Review Manager (RevMan) [Computer program]. Version 5.4. Copenhagen: The Nordic Cochrane Center, The Cochrane Collaboration, 2014.

14. GRADEpro GDT: GRADEpro Guideline Development Tool [Software]. McMaster University, 2015 (developed by Evidence Prime, Inc.). gradepro. org.

15. Arnett FC, Edworthy SM, Bloch DA, McShane DJ, Fries JF, Cooper NS, et al. The American Rheumatism Association 1987 revised criteria for the classification of rheumatoid arthritis. Arthritis Rheum. 1988;31:315-24.

16. Aletaha D, Neogi T, Silman AJ, et al. 2010 Rheumatoid arthritis classification criteria: an American College of Rheumatology/European League Against Rheumatism collaborative initiative. Arthritis Rheum. 2010;62(9):2569-81. https://doi.org/10.1002/art.27584.

17. Lee EB, Fleischmann R, Hall S, Wilkinson B, Bradley JD, Gruben D, et al. Tofacitinib versus methotrexate in rheumatoid arthritis. N Engl J Med. 2014;19(370):2377-86.

18. Fleischmann R, Schiff M, van der Heijde D, Ramos-Remus C, Spindler A, Stanislav $M$, et al. Baricitinib, methotrexate, or combination in patients with rheumatoid arthritis and no or limited prior disease-modifying antirheumatic drug treatment. Arthritis Rheumatol. 2017;69:506-17.

19. van Vollenhoven $R$, Takeuchi T, Pangan AL, et al. Efficacy and safety of upadacitinib monotherapy in methotrexate-naïve patients with moderately to severely active rheumatoid arthritis (SELECT-EARLY): a randomized, double-blind, active-comparator, multi-center, multi-country trial [published online ahead of print, 2020 Jul 8]. Arthritis Rheumatol. 2020. https://doi.org/10.1002/art.41384.

20. Li Z, Hu J, Bao C, Li X, Xu J, Spindler A, et al. SAT0218 Efficacy and safety of baricitinib in mtx-ir patients with rheumatoid arthritis: 52 week results from a phase 3 study (RA-BALANCE). Ann Rheum Dis. 2018;77(Suppl 2):969.

21. Tanaka Y, Takeuchi T, Yamaoka K, Oribe M, Kawano M, Zhou Y, et al. SAT0257 a phase 2b/3 randomised, placebo-controlled, double-blind study of upadacitinib, a selective jak1 inhibitor, in japanese patients with active rheumatoid arthritis and inadequate response to conventional synthetic dmards. Ann Rheum Dis. 2018;77(Suppl 2):991.

22. Burmester GR, Kremer JM, Van den Bosch F, Kivitz A, Bessette L, Li Y, et al. Safety and efficacy of upadacitinib in patients with rheumatoid arthritis and inadequate response to conventional synthetic disease-modifying anti-rheumatic drugs (SELECT-NEXT): a randomised, double-blind, placebo-controlled phase 3 trial. Lancet. 2018;391(10139):2503-12.

23. Dougados M, van der Heijde D, Chen YC, Greenwald M, Drescher E, Liu J, et al. Baricitinib in patients with inadequate response or intolerance to conventional synthetic DMARDs: results from the RA-BUILD study. Ann Rheum Dis. 2017;76(1):88-95.

24. Taylor PC, Keystone EC, van der Heijde D, Weinblatt ME, Del Carmen ML, Reyes Gonzaga J, et al. Baricitinib versus placebo or adalimumab in rheumatoid arthritis. N Engl J Med. 2017;376(7):652-62.

25. Tanaka Y, Emoto K, Cai Z, Aoki T, Schlichting D, Rooney T, et al. Efficacy and safety of baricitinib in japanese patients with active rheumatoid arthritis receiving background methotrexate therapy: a 12-week, double-blind, randomized placebo-controlled study. J Rheumatol. 2016;43(3):504-11.

26. Keystone EC, Taylor PC, Drescher E, Schlichting DE, Beattie SD, Berclaz PY, et al. Safety and efficacy of baricitinib at 24 weeks in patients with rheumatoid arthritis who have had an inadequate response to methotrexate. Ann Rheum Dis. 2015:74(2):333-40.

27. Westhovens R, Taylor PC, Alten R, Pavlova D, Enríquez-Sosa F, Mazur M, et al. Filgotinib (GLPG0634/GS-6034), an oral JAK1 selective inhibitor, is effective in combination with methotrexate (MTX) in patients with active rheumatoid arthritis and insufficient response to MTX: results from a randomised, dose-finding study (DARWIN 1). Ann Rheum Dis. 2017;76(6):998-1008. 
28. Kavanaugh A, Kremer J, Ponce L, Cseuz R, Reshetko OV, Stanislavchuk M et al. Filgotinib (GLPG0634/GS-6034), an oral selective JAK1 inhibitor, is effective as monotherapy in patients with active rheumatoid arthritis: results from a randomised, dose-finding study (DARWIN 2). Ann Rheum Dis. 2017;76(6):1009-19.

29. Takeuchi T, Tanaka Y, Tanaka S, Kawakami A, Iwasaki M, Katayama K, et al Efficacy and safety of peficitinib (ASP015K) in patients with rheumatoid arthritis and an inadequate response to methotrexate: results of a phase III randomised, double-blind, placebo-controlled trial (RAJ4) in Japan. Ann Rheum Dis. 2019;78(10):1305-19.

30. Kivitz AJ, Gutierrez-Ureña SR, Poiley J, Genovese MC, Kristy R, Shay K, et al. Peficitinib, a JAK inhibitor, in the treatment of moderate-to-severe rheumatoid arthritis in patients with an inadequate response to methotrexate. Arthritis Rheumatol. 2017;69(4):709-19.

31. Fleischmann R, Mysler E, Hall S, Kivitz AJ, Moots RJ, Luo Z, et al. Efficacy and safety of tofacitinib monotherapy, tofacitinib with methotrexate, and adalimumab with methotrexate in patients with rheumatoid arthritis (ORAL Strategy): a phase 3b/4, double-blind, head-to-head, randomised controlled trial. Lancet. 2017;390(10093):457-68.

32. van der Heijde D, Tanaka Y, Fleischmann R, Keystone E, Kremer J, Zerbini C, et al. Tofacitinib (CP-690,550) in patients with rheumatoid arthritis receiving methotrexate: twelve-month data from a twenty-four-month phase III randomized radiographic study. Arthritis Rheum. 2013;65(3):559-70.

33. van Vollenhoven RF, Fleischmann R, Cohen S, Lee EB, García Meijide JA, Wagner S, et al. Tofacitinib or adalimumab versus placebo in rheumatoid arthritis. N Engl J Med. 2012;367(6):508-19.

34. Kremer JM, Cohen S, Wilkinson BE, Connell CA, French JL, Gomez-Reino J, et al. A phase Illb dose-ranging study of the oral JAK inhibitor tofacitinib (CP-690,550) versus placebo in combination with background methotrexate in patients with active rheumatoid arthritis and an inadequate response to methotrexate alone. Arthritis Rheum. 2012;64(4):970-81.

35. Tanaka Y, Suzuki M, Nakamura H, Toyoizumi S, Zwillich SH. Phase II study of tofacitinib (CP-690,550) combined with methotrexate in patients with rheumatoid arthritis and an inadequate response to methotrexate. Arthritis Care Res (Hoboken). 2011;63(8):1150-8.

36. Smolen JS, Pangan AL, Emery P, Rigby W, Tanaka Y, Vargas Jl, et al. Upadacitinib as monotherapy in patients with active rheumatoid arthritis and inadequate response to methotrexate (SELECT-MONOTHERAPY): a randomised, placebo-controlled, double-blind phase 3 study. Lancet. 2019;393(10188):2303-11

37. Genovese MC, Smolen JS, Weinblatt ME, Burmester GR, Meerwein S, Camp HS, et al. Efficacy and safety of ABT-494, a selective JAK-1 inhibitor, in a phase Ilb study in patients with rheumatoid arthritis and an inadequate response to methotrexate. Arthritis Rheumatol. 2016;68(12):2857-66.

38. Fleischmann R, Pangan AL, Song $I H$, Mysler E, Bessette L, Peterfy C, et al. Upadacitinib versus placebo or adalimumab in patients with rheumatoid arthritis and an inadequate response to methotrexate: results of a phase III, double-blind, randomized controlled trial. Arthritis Rheumatol. 2019;71(11):1788-800.

39. Burmester GR, Blanco R, Charles-Schoeman C, Wollenhaupt J, Zerbini C, Benda B, et al. Tofacitinib (CP-690,550) in combination with methotrexate in patients with active rheumatoid arthritis with an inadequate response to tumor necrosis factor inhibitors: a randomized phase 3 trial. Lancet. 2013;9(381):451-60.

40. Genovese MC, Kremer J, Zamani O, Ludivico C, Krogulec M, Xie L, Beattie $\mathrm{SD}$, et al. Baricitinib in patients with refractory rheumatoid arthritis. $\mathrm{N}$ Engl J Med. 2016;31(374):1243-52.

41. Genovese MC, Fleischmann R, Combe B, Hall S, Rubbert-Roth A, Zhang $Y$, et al. Safety and efficacy of upadacitinib in patients with active rheumatoid arthritis refractory to biologic disease-modifying anti-rheumatic drugs (SELECT-BEYOND): a double-blind, randomized controlled phase 3 trial. Lancet. 2018;23(391):2513-24.

42. Genovese MC, Kalunian K, Gottenberg JE, Mozaffarian N, Bartok B, Matzkies $F$, et al. Effect of filgotinib vs. placebo on clinical response in patients with moderate to severe rheumatoid arthritis refractory to disease-modifying antirheumatic drug therapy: the FINCH 2 randomized clinical trial. JAMA. 2019;322:315-25.

43. Conaghan PG, Østergaard M, Bowes MA, Wu C, Fuerst T, van der Heijde D, Irazoque-Palazuelos F, Soto-Raices O, Hrycaj P, Xie Z, Zhang R. Comparing the effects of tofacitinib, methotrexate and the combination, on bone marrow oedema, synovitis and bone erosion in methotrexate-naive, early active rheumatoid arthritis: results of an exploratory randomized MRI study incorporating semiquantitative and quantitative techniques. Ann Rheum Dis. 2016;75(6):1024-33.

44. Fleischmann R, Schiff M, van der Heijde D, Ramos-Remus C, Spindler A, Stanislav M, Zerbini CA, Gurbuz S, Dickson C, de Bono S, Schlichting D. Baricitinib, methotrexate, or combination in patients with rheumatoid arthritis and no limited prior disease — modifying antirheumatic drug treatment. Arthritis \& Rheumatology. 2017;69(3):506-17.

45. Fleischmann R, Mysler E, Hall S, Kivitz AJ, Moots RJ, Luo Z, DeMasi R, Soma K, Zhang R, Takiya L, Tatulych S. Efficacy and safety of tofacitinib monotherapy, tofacitinib with methotrexate, and adalimumab with methotrexate in patients with rheumatoid arthritis (ORAL Strategy): a phase 3b/4, double-blind, head-to-head, randomised controlled trial. The Lancet. 2017;390(10093):457-68.

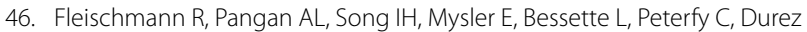
P, Ostor AJ, Li Y, Zhou Y, Othman AA. Upadacitinib versus placebo or adalimumab in patients with rheumatoid arthritis and an inadequate response to methotrexate: results of a phase iii, double-blind, randomized controlled trial. Arthritis Rheumatol. 2019;71(11):1788-800.

47. Hall S, Nash P, Rischmueller M, Bossingham D, Bird P, Cook N, Witcombe D, Soma K, Kwok K, Thirunavukkarasu K. Tofacitinib, an oral Janus Kinase inhibitor: pooled efficacy and safety analyses in an Australian rheumatoid arthritis population. Rheumatol Ther. 2018;5(2):383-401.

48. Taylor PC, Keystone EC, van der Heijde D, Weinblatt ME, del Carmen ML, Reyes Gonzaga J, Yakushin S, Ishii T, Emoto K, Beattie S, Arora V. Baricitinib versus placebo or adalimumab in rheumatoid arthritis. N Engl J Med. 2017;376(7):652-62.

49. Jansen JP, Incerti D, Mutebi A, Peneva D, MacEwan JP, Stolshek B, Kaur $P$, Gharaibeh M, Strand V. Cost-effectiveness of sequenced treatment of rheumatoid arthritis with targeted immune modulators. J Med Econ. 2017;20(7):703-14.

50. Wehler E, Boytsov N, Nicolay C, Herrera-Restrepo O, Kowal S. A Budget impact and cost per additional respond analysis for baricitinib for the treatment of moderate-to-severe rheumatoid arthritis in patients with an inadequate response to tumor necrosis factor inhibitors in the USA. Pharmacoeconomics. 2020;38(1):39-56.

51. Critical Appraisal Skills Programme. CASP economic evaluation checklist.

52. Chen DY, Hsu PN, Tang CH, Claxton L, Valluri S, Gerber RA. Tofacitinib in the treatment of moderate-to-severe rheumatoid arthritis: a costeffectiveness analysis compared with adalimumab in Taiwan. J Med Econ. 2019:22(8):777-87.

53. Claxton L, Jenks M, Taylor M, Wallenstein G, Mendelsohn AM, Bourret JA, Singh A, Moynagh D, Gerber RA. An economic evaluation of tofacitinib treatment in rheumatoid arthritis: modeling the cost of treatment strategies in the United States. J Manag Care Spec Pharm. 2016;22(9):1088-102.

54. Lee MY, Park SK, Park SY, Byun JH, Lee SM, Ko SK, Lee EK. Cost-effectiveness of tofacitinib in the treatment of moderate to severe rheumatoid arthritis in South Korea. Clin Ther. 2015;37(8):1662-76.

55. Navarro F, Martinez-Sesmero JM, Balsa A, Peral C, Montoro M, Valderrama M, Gómez S, de Andrés-Nogales F, Casado MA, Oyagüez I. Cost-effectiveness analysis of treatment sequences containing tofacitinib for the treatment of rheumatoid arthritis in Spain. Clin Rheumatol. 2020;17:1-2.

56. Schlueter M, Finn E, Díaz S, Dilla T, Inciarte-Mundo J, Fakhouri W. Costeffectiveness analysis of baricitinib versus adalimumab for the treatment of moderate-to-severe rheumatoid arthritis in Spain. ClinicoEconomics Outcomes Res: CEOR. 2019;11:395.

57. Van De Laar CJ, Voshaar MA, Fakhouri WK, Zaremba-Pechmann L, De Leonardis F, De La Torre I, Van De Laar MA. Cost-effectiveness of a JAK1/ JAK2 inhibitor vs a biologic disease-modifying antirheumatic drug (bDMARD) in a treat-to-target strategy for rheumatoid arthritis. ClinicoEconomics Outcomes Res: CEOR. 2020;12:213.

58. Curtis JR, Xie F, Yun H, et al. Real-world comparative risks of herpes virus infections in tofacitinib and biologic-treated patients with rheumatoid arthritis. Ann Rheum Dis. 2016;75:1843-7.

59. Winthrop KL, Curtis JR, Lindsey S, et al. Herpes zoster and tofacitinib: clinical outcomes and the risk of concomitant therapy. Arthritis Rheumatol. 2017;69(10):1960-8

60. Calabrese LH, Abud-Mendoza C, Lindsey SM, Lee SH, Tatulych S, Takiya $L$, et al. Live zoster vaccine in patients with rheumatoid arthritis treated with tofacitinib with or without methotrexate, or adalimumab with 
methotrexate: a post hoc analysis of data from a phase IIIb/IV randomized study. Arthritis Care Res (Hoboken). 2020;72:353-9.

61. Winthrop KL, Wouters AG, Choy EH, Soma K, Hodge JA, Nduaka Cl, et al. The safety and immunogenicity of live zoster vaccination in patients with rheumatoid arthritis before starting tofacitinib: a randomized phase II trial. Arthritis Rheumatol. 2017;69:1969-77.

62. Winthrop KL, Wouters A, Choy EH, Chen C, Biswas P, Wang L, et al. Long-term effectiveness of live herpes zoster vaccine in patients with rheumatoid arthritis subsequently treated with tofacitinib. Ann Rheum Dis. 2020;79:669-71.

63. Stevens E, Weinblatt ME, Massarotti E, Griffin F, Emani S, Desai S. Safety of the zoster vaccine recombinant adjuvanted in rheumatoid arthritis and other systemic rheumatic disease patients: a single center's experience with 400 patients. ACR Open Rheumatol. 2020. https://doi.org/10.1002/ acr2.11150.

64. Fleischmann R, Kremer J, Cush J, et al. Placebo-controlled trial of tofacitinib monotherapy in rheumatoid arthritis. N Engl J Med. 2012;367(6):495-507. https://doi.org/10.1056/NEJMoa1109071.

65. van Vollenhoven RF, Fleischmann R, Cohen S, et al. Tofacitinib or adalimumab versus placebo in rheumatoid arthritis [published correction appears in N Engl J Med. 2013 Jul 18;369(3):293]. N Engl J Med. 2012;367(6):508-19. https://doi.org/10.1056/NEJMoa111207.

66. Burmester GR, Blanco R, Charles-Schoeman C, et al. Tofacitinib (CP690,550) in combination with methotrexate in patients with active rheumatoid arthritis with an inadequate response to tumour necrosis factor inhibitors: a randomised phase 3 trial. Lancet. 2013;381 (9865):451-60. https://doi.org/10.1016/S0140-6736(12)61424-X.

67. Genovese MC, Fleischmann R, Combe B, et al. Safety and efficacy of upadacitinib in patients with active rheumatoid arthritis refractory to biologic disease-modifying anti-rheumatic drugs (SELECT-BEYOND): a doubleblind, randomised controlled phase 3 trial. Lancet. 2018;391(10139):251324. https://doi.org/10.1016/S0140-6736(18)31116-4.

68. Burmester GR, Kremer JM, Van den Bosch F, et al. Safety and efficacy of upadacitinib in patients with rheumatoid arthritis and inadequate response to conventional synthetic disease-modifying anti-rheumatic drugs (SELECT-NEXT): a randomised, double-blind, placebo-controlled phase 3 trial. Lancet. 2018;391(10139):2503-12. https://doi.org/10.1016/ S0140-6736(18)31115-2.
69. Fleischmann R, Pangan AL, Song $\mathbb{H}$, et al. Upadacitinib versus placebo or adalimumab in patients with rheumatoid arthritis and an inadequate response to methotrexate: results of a phase III, double-blind, randomized controlled trial. Arthritis Rheumatol. 2019;71(11):1788-800. https://doi.org/10.1002/art.41032.

70. Tanaka Y, Emoto K, Cai Z, Aoki T, Schlichting D, Rooney T, Macias W. Efficacy and safety of baricitinib in japanese patients with active rheumatoid arthritis receiving background methotrexate therapy: a 12-week, doubleblind, randomized placebo-controlled study. J Rheumatol. 2016;43(5):998 https://doi.org/10.3899/jrheum.150613.C1.

71. Dougados M, van der Heijde D, Chen YC, et al. Baricitinib in patients with inadequate response or intolerance to conventional synthetic DMARDs: results from the RA-BUILD study [published correction appears in Ann Rheum Dis. 2017 Sep;76(9):1634]. Ann Rheum Dis. 2017;76(1):88-95. https://doi.org/10.1136/annrheumdis-2016-210094.

72. Taylor PC, Keystone EC, van der Heijde D, et al. Baricitinib versus placebo or adalimumab in rheumatoid arthritis. N Engl J Med. 2017;376(7):652-62. https://doi.org/10.1056/NEJMoa1608345.

73. Genovese MC, Kalunian K, Gottenberg JE, et al. Effect of filgotinib vs placebo on clinical response in patients with moderate to severe rheumatoid arthritis refractory to disease-modifying antirheumatic drug therapy: the FINCH 2 randomized clinical trial [published correction appears in JAMA. 2020 Feb 4;323(5):480]. JAMA. 2019;322(4):315-25. https://doi.org/ 10.1001/jama.2019.9055.

74. https://clinicaltrials.gov/ct2/show/results/NCT02092467. Last checked in 30 Sept 2021.

75. https://www.fda.gov/drugs/drug-safety-and-availability/fda-requi res-warnings-about-increased-risk-serious-heart-related-events-cancerblood-clots-and-death. Last checked in 30 Sept 2021.

76. https://www.ema.europa.eu/en/news/meeting-highlights-pharmacovi gilance-risk-assessment-committee-prac-7-10-june-2021. Last checked in 30 Sept 2021

\section{Publisher's Note}

Springer Nature remains neutral with regard to jurisdictional claims in published maps and institutional affiliations.
Ready to submit your research? Choose BMC and benefit from:

- fast, convenient online submission

- thorough peer review by experienced researchers in your field

- rapid publication on acceptance

- support for research data, including large and complex data types

- gold Open Access which fosters wider collaboration and increased citations

- maximum visibility for your research: over $100 \mathrm{M}$ website views per year

At BMC, research is always in progress.

Learn more biomedcentral.com/submissions 